\title{
Heavily fluorinated carbohydrates as enzyme substrates: oxidation of tetrafluorinated galactose by galactose oxidase
}

Avgousta Ioannou, Elena Cini, Roxana S. Timofte, Sabine L. Flitsch, Nicholas J. Turner and Bruno Linclau

School of Chemistry, University of Southampton, Southampton UK SO17 1BJ. Email: Bruno.linclau@soton.ac.uk

Please cite this paper as:

Chem Commun., 2011 , (47) 11228-11230

The publisher's version of this paper is available here: http://dx.doi.org/10.1039/C1CC13956H

\author{
Related articles by Dr Bruno Linclau can be found below: \\ Bruno Linclau, Samuel Golten, Mark Light, Muriel Sebban, Hassan Ouladi (2011) The \\ conformation of tetrafluorinated methyl galactoside anomers: crystallographic and NMR \\ studies. Carbohydr Res, (346) 1129-1139 (doi: 10.1016/j.carres.2011.04.007) \\ Bruno Linclau, A. James Boydell, Roxana S. Timofte, Kylie J. Brown, Victoria \\ Vinader and Alexander C. Weymouth-Wilson, (2009) Enantioselective synthesis of \\ tetrafluorinated ribose and fructose. Org. Biomol Chem., 7, 803-814 \\ (doi:10.1039/B817260A) \\ Roxana S. Timofte and Bruno Linclau, (2008) Enantioselective Synthesis of \\ Tetrafluorinated Glucose and Galactose. Org Lett., 10 (17) 3673-3676 \\ (doi:10.1021/ol801272e) \\ James Boydell, Victoria Vinader, Bruno Linclau (2004) Enantioselective Synthesis of \\ Tetrafluoroethylene-Containing Monosaccharides. Angewandte Chemie, (43) 5677-5679 \\ (doi: 10.1002/anie.200460746)
}




\title{
Heavily fluorinated carbohydrates as enzyme substrates: oxidation of tetrafluorinated galactose by galactose oxidase $\dagger$
}

\author{
Avgousta Ioannou, ${ }^{a}$ Elena Cini, ${ }^{b}$ Roxana S. Timofte, ${ }^{b}$ Sabine L. Flitsch, ${ }^{*} a$ \\ Nicholas J. Turner ${ }^{* a}$ and Bruno Linclau ${ }^{* b}$
}

Received 2nd July 2011, Accepted 22nd August 2011

DOI: $10.1039 / \mathrm{clcc13956h}$

Galactose oxidase (GOase) was shown to oxidise several C2/C3 fluorinated galactose analogues. Interestingly, the enzyme was able to distinguish between the 2,3-tetrafluorinated galactose and its epimeric glucose analogue, and this represents the first reported biotransformation of a heavily fluorinated sugar.

The systematic and selective replacement of individual hydroxyl groups of carbohydrates by hydrogen or fluorine is a useful method for the investigation of protein-carbohydrate interactions. ${ }^{1}$ The difference in binding constant between the parent sugar, the deoxy- and (mono)deoxyfluorinated analogues reveals the importance and role of particular hydroxy groups in the interaction with the receptor.

Interactions with highly electronegative fluorine atoms are dominated by electrostatic effects. Seminal work from the Diederich group has established that electropositive centres engaging in interactions with $\mathrm{C}-\mathrm{F}$ not only include $\mathrm{X}-\mathrm{H}$ hydrogen atoms, but also carbonyl and guanidinium groups. ${ }^{2}$ Interestingly, such attractive multipolar interactions involving fluorinated carbohydrates have been reported. ${ }^{3}$

By investigating affinities of deoxy and deoxyfluorosugars for the glucose binding site in glycogen phosphorylase, Withers et al. have observed that vicinal 1,2-dideoxy-1,2-difluorosugars have a higher affinity than predicted (with the opposite effect for the 1,2-dideoxy substrate), and that the absolute configuration at the fluorination site remains important. ${ }^{1 d}$ This observation has been rationalised by the resultant larger hydrophobic domain, with hydrophobic desolvation contributing to binding. ${ }^{4 b}$ For polyfluorinated moieties, the combination of attractive multipolar interactions and hydrophobic desolvation, which are both expected to contribute favourably to binding, has been termed "polar hydrophobicity". ${ }^{4}$ This has emerged as an appealing strategy to overcome the issue of typically low protein-carbohydrate

${ }^{a}$ MIB \& School of Chemistry, The University of Manchester,

131 Princess Street, Manchester, M1 7DN, UK.

E-mail: sabine.flitsch@manchester.ac.uk,

nicholas.turner@manchester.ac.uk; Fax: +44 (0) 161 2751311;

Tel: + 44 (0) $1613065172 / 5173$

${ }^{b}$ School of Chemistry, University of Southampton, Highfield,

Southampton SO171BJ, UK. E-mail: bruno.linclau@soton.ac.uk;

Fax: + 44 (0) 238059 3781; Tel: + 44 (0)23 80593816

$\dagger$ Electronic supplementary information (ESI) available: synthesis and characterisation of novel compounds, conditions of GOase experiments. See DOI: $10.1039 / \mathrm{clcc} 13956 \mathrm{~h}$ binding affinity and to address the excessively hydrophilic nature of carbohydrates. ${ }^{4}$ Synthetic methodology towards different types of heavily fluorinated carbohydrate mimetics has been reported in recent years. ${ }^{4,5}$

To the best of our knowledge, heavily fluorinated monosaccharides as substrates for enzymatic reactions have not been reported to date. ${ }^{6}$ Here we report the first experiments which demonstrate not only a reasonably efficient conversion of tetrafluorogalactose by the enzyme galactose oxidase (GOase), but also that the enzyme is able to discriminate between tetrafluorinated galactose and its glucose epimer, which is not turned over.

GOase catalyses the oxidation of the 6-OH of D-galactose 1 (D-Gal) to the corresponding aldehyde as shown in Scheme $1{ }^{7}$ and has great potential for applications in biotechnology. ${ }^{8}$ It is a suitable system to investigate effects of fluorination upon binding for a number of reasons. Firstly, the low affinity of GOase for D-Gal $\left(\mathrm{K}_{\mathrm{M}} 50 \mathrm{mM}\right)$ should permit detection of beneficial effects on the binding, and the high $\mathrm{k}_{\text {cat }}$ value $\left(362 \mathrm{~s}^{-1}\right)$ ensures much slower analogues will be detectable (an assay for GOase that allows the detection of substrates with $\mathrm{k}_{\text {cat }}$ values as low as ca $1 \mathrm{~s}^{-1}$ is available). ${ }^{9}$ Secondly GOase has a well-defined active site (see below). ${ }^{10 a}$ Thirdly, fluorination at $\mathrm{C} 2 / \mathrm{C} 3$ is unlikely to have a significant impact on the intrinsic reactivity of the 6-hydroxyl group, ensuring that any influence on the $\mathrm{k}_{\mathrm{cat}}$ values is not caused by changes in inherent reactivity of the substrate.

Although there is no crystal structure of the GOase-Gal complex, the crystal structure of the native enzyme has been solved and a substrate-binding model is available (Fig. 1). ${ }^{10}$ Arg330 forms an H-bond between both NH's and the 4-OH. Gln206 is an H-bond acceptor for 3-OH. The 6-OH is an $\mathrm{H}$-bond donor to the deprotonated Tyr495. The 5-O atom is engaged in a H-bond with Trp290. The 1-OH and 2-OH are exposed to the solvent and a hydrophobic contact occurs via the sugar B-face involving C3 and C4 with Phe464 (not shown).<smiles>OC[C@H]1O[C@H](O)[C@@H](O)[C@H](O)[C@H]1O</smiles>
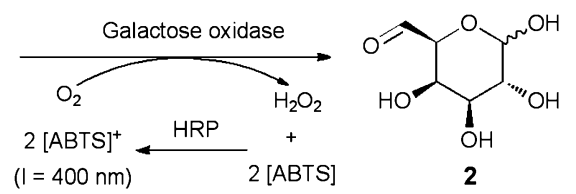

Scheme 1 Oxidation of D-Gal by GOase, with colorimetric assay for detection of activity (ABTS $=2,2^{\prime}$-azino-bis(3-ethylbenzothiazoline6-sulphonic acid)). 

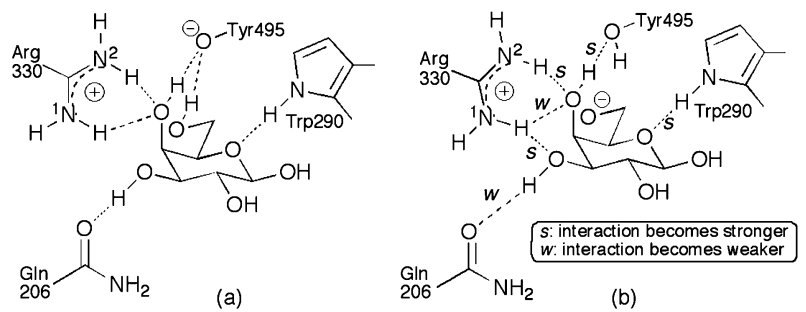

Fig. 1 Schematic representation of the key Gal-GOase interactions in the ground state (a) and in the transition state (b).

This model assigns an important role for Arg330, which is supported by mutagenesis experiments. ${ }^{11}$ The $R 330 \mathrm{~A}$ mutant leads to a 22-fold increase in $\mathrm{K}_{\mathrm{M}}$ value (to $2.2 \mathrm{M}$ ) for $\mathrm{D}-\mathrm{Gal}$, associated with a 12.6-fold reduction in $\mathrm{k}_{\text {cat }}$ (to $84 \mathrm{~s}^{-1}$ ). In addition, the axial 4-OH group of $\mathrm{Gal}$ is crucial, as demonstrated by the complete rejection of D-glucose and D-mannose by the enzyme. $^{7,12 a}$ Modifications at $\mathrm{C} 2$ and $\mathrm{C} 3$ are well-tolerated: methylation at the 2- and 3-position, and inversion at $\mathrm{C} 2$ (D-talose) are allowed, with relative reaction rates for oxidation being $50 \%, 172 \%$, and $52 \%$ compared to D-Gal. ${ }^{12 a, b}$ Interestingly, the 2,3-dimethylated sugar is also a good substrate $(76 \%$ relative oxidation rate). ${ }^{12 b}$

Taking into account the above model of active site:substrate interactions, the tetrafluorinated galactose derivative $\mathbf{5}$ was considered to be a potential substrate for GOase, and the tetrafluorinated glucose $\mathbf{6}$ as a suitable negative control. Importantly, tetrafluorinated galactose derivatives were shown to possess the typical sugar ${ }^{4} C_{1}$ conformation. ${ }^{13}$ Preliminary experiments involving $\mathbf{3}$ and $\mathbf{4}$ showed not only that fluorination at $\mathrm{C} 2$ and $\mathrm{C} 3$ was allowed for GOase mediated oxidation, but also revealed surprising kinetic parameters.

The synthesis of $\mathbf{3}$ was achieved by deprotection of the corresponding known $^{14}$ tri-acetate, which is accessible in 3 steps from tri- $O$-acetyl-D-galactal. The monofluorinated $\mathbf{4}^{15}$ and tetrafluorinated $\mathbf{5}$ and $\mathbf{6}^{5 d}$ are known compounds.

The relative rate of reaction of WT GOase with each substrate 3-6, and with D-Gal, was determined at $50 \mathrm{mM}$ concentration (Table 1, col 2). Both $\mathbf{3}$ and $\mathbf{4}$ appear to be good substrates for oxidation by WT GOase, showing similar reaction rates (approximately $50 \%$ of $\mathrm{D}-\mathrm{Gal} \mathbf{1}$ ). In contrast, the tetrafluorinated derivative $\mathbf{5}$ is a poor substrate compared to $\mathrm{D}-\mathrm{Gal}$. However, the substrate concentration employed in the assay is much lower than the $K_{M}$ value of $\mathbf{5}$, which exacerbates the decrease in turnover. Interestingly, the tetrafluorinated glucose derivative $\mathbf{6}$ is not turned over. It is significant that the high degree of substrate fluorination does not impair the ability of the enzyme to discriminate between these two substrate analogues and only the tetrafluorinated galactose $\mathbf{5}$ is bound with sufficient affinity by the active site.

The intrinsic kinetic parameters of the fluorinated sugars 3-5 were determined (Table 1, col 3-5) with the values for D-Gal provided for comparison. The $\mathrm{k}_{\text {cat }}$ values for $\mathbf{3}$ and $\mathbf{4}$ are $30 \%$ and $21 \%$ respectively of the D-Gal value, thus slightly reduced. The $\mathrm{k}_{\text {cat }}$ value for the tetrafluorinated substrate $\mathbf{5}$ is further reduced to $8 \%$ of the $\mathrm{D}-\mathrm{Gal}$ value, but enzyme activity is still significant. The $K_{M}$ value for $\mathbf{3}$ is similar, and that of 4 even lower than for D-Gal, while the tetrafluorinated $\mathbf{5}$ has a nine-fold increased $\mathrm{K}_{M}$ value.
Table 1 Summary of activity and steady-state kinetic parameters for the oxidation of fluorinated analogues of D-Gal by WT GOase ${ }^{a}$

\begin{tabular}{|c|c|c|c|c|c|}
\hline Sugar & $\begin{array}{c}\mathrm{V}_{\text {rel }} \\
\text { GOase } \\
\left(\mathrm{mAU} \mathrm{min}^{-1}\right)\end{array}$ & $\mathrm{k}_{\mathrm{cat}}\left(\mathrm{s}^{-1}\right)$ & $\mathrm{K}_{\mathrm{M}}(\mathrm{M})$ & $\begin{array}{c}\mathrm{k}_{\mathrm{cat}} / \mathrm{K}_{\mathrm{M}} \\
\left(\mathrm{M}^{-1} \mathrm{~s}^{-1}\right)\end{array}$ & $\begin{array}{c}\Delta \Delta G_{b} \\
\left(\mathrm{kcal} \mathrm{mol}^{-1}\right)\end{array}$ \\
\hline -Gal 1 & $3050 \pm 9^{a}$ & $362 \pm 7^{a}$ & $0.05 \pm 0.002$ & $7240 \pm 150$ & - \\
\hline 3 & $1900 \pm 100$ & $107 \pm 11$ & $0.06 \pm 0.01$ & $1800 \pm 200$ & 0.8 \\
\hline 4 & $1470 \pm 270$ & $79 \pm 8$ & $0.03 \pm 0.01$ & $2600 \pm 500$ & 0.6 \\
\hline 5 & $240 \pm 1$ & $29 \pm 1$ & $0.44 \pm 0.03$ & $65 \pm 3$ & 2.8 \\
\hline 6 & & - & - & - & - \\
\hline
\end{tabular}

${ }^{a}$ The WT GOase is His-tagged to aid purification, resulting in slightly different kinetics to published data with other WT GOases. See SI for assay details. ${ }^{\dagger b}$ No activity was observed.

In attempting to interpret these values, alongside the direct interactions involving $\mathrm{C}-\mathrm{F}$, the influence of fluorination on the adjacent functional groups ${ }^{16,17}$ must also be considered. ${ }^{18}$ In particular, a $\mathrm{CF}_{2}$-group will significantly increase the hydrogen bond donating and decrease the accepting capacity of a vicinal alcohol group. Finally the influence on $\mathrm{C}-\mathrm{H} \cdots \pi$ interactions, which are also important for protein-carbohydrate interactions, ${ }^{1 d, 19}$ should be taken into account.

Within error, the $K_{M}$ values for $\mathbf{3}$ and $\mathbf{4}$ indicate that both these fluorosugars are at least as effective in binding to GOase as D-Gal 1. The replacement in 3 of $2-\mathrm{CHOH}$ with $\mathrm{CF}_{2}$, considered as sterically conservative albeit with different directionality, ${ }^{4 b}$ should significantly increase the 3-OH hydrogen bond donating capacity to $\mathrm{Gln} 206$, leading to a decreased $\mathrm{K}_{\mathrm{M}}$ value. Interestingly, the $\mathrm{K}_{\mathrm{M}}$ of 2-deoxy-D-Gal is double the value of the $\mathrm{K}_{\mathrm{M}}$ of $\mathrm{D}-\mathrm{Gal} \mathbf{1}^{7 a}$

Despite the apparent electrostatic repulsion between the 3-F and the Gln206 carbonyl group and/or the loss of hydrogen bond donating capacity, the $\mathrm{K}_{\mathrm{M}}$ value for $\mathbf{4}$ is even lower than the $\mathrm{K}_{\mathrm{M}}$ for $\mathbf{1}$. This is remarkable and could indicate that an attractive Gln206 N-H . F interaction is established, or that the 3-fluoro group became involved in an attractive interaction with the guanidinium group ${ }^{2}$ in $\operatorname{Arg} 330$. Moreover, the fluorination could have a beneficial effect on the $\mathrm{C} 3-\mathrm{H} \cdots \pi$ interaction involving Phe464 due to an increased $\mathrm{C}-\mathrm{H}$ acidity (such an effect may also be expected for 3 ).

Assuming GOase follows Michaelis-Menten behaviour, ${ }^{12 c}$ and that the fluorination has negligible influence on the oxidation reaction, a comparison of binding energies $\left(\Delta \Delta G_{b}\right)$, which is based on the difference in specificity constants of the substrates, is of interest since binding energy can be translated into lower activation energies (Table 1, col 4,5). ${ }^{20}$ For 3 and 4, the $\Delta \Delta G_{b}$ is within the range of an uncharged donor/acceptor pair, ${ }^{1 c}$ with a larger loss for 3 compared to 4 . This could be interpreted with the model for the transition state of the oxidation, which indicates that the $3-\mathrm{OH}$ becomes a hydrogen bond acceptor for Arg330 (Fig. 2b), ${ }^{10}$ which will be hampered by the adjacent $\mathrm{C} 2$ difluorination, but tolerated when a 3-fluoro group is present.

Given that the fluorination at the 2 and 3-position for $\mathbf{3}$ and 4 does not impede binding to WT GOase, the much-increased $\mathrm{K}_{\mathrm{M}}$ value for $\mathbf{5}$ is rather surprising. A steric/stereoelectronic clash of the axial 3-F with Phe464 is possible. D-Gulose (3-epi-D-Gal) is not a substrate for GOase. ${ }^{12 a}$ However, given the minimal steric perturbation at that position we suggest that this can only be a minor factor. In addition, the repulsion of a $\mathrm{C}-\mathrm{F}$ group with a benzene $\pi$ system $^{21}$ appears to be 


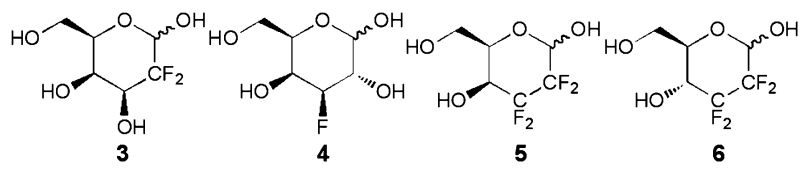

Fig. 2 Fluorinated galactose analogues 3-5, and glucose analogue 6.

minimal, ${ }^{21 b}$ and calculations suggest that this interaction for a FC-F group could be slightly attractive. ${ }^{21 c}$

Instead we believe that the electronic influence of the tetrafluorination at $\mathrm{C} 2$ and $\mathrm{C} 3$ on the axial $4-\mathrm{OH}$ group dominates the interaction of $\mathbf{5}$ with the GOase active site. The 4-OH is a key hydrogen bond acceptor for the guanidinium group of the Arg330. Its importance is not only illustrated by the aforementioned inactivity of D-Glc, the 4-epimer of $\mathbf{1}$, but also by a 13 -fold increase in $\mathrm{K}_{\mathrm{M}}$ upon replacing of the 4-OH group with fluorine ${ }^{12 c}$ or the very low reactivity of the 4-deoxy and 4-methoxy substrates which can be attributed to the loss of hydrogen bond donating capacity or steric reasons. ${ }^{12 b, c}$ While the tetrafluorination at $\mathrm{C} 2 / 3$ will enhance the hydrogen bond donating capacity, as explained above, there is a simultaneous significant reduction in hydrogen bond acceptor capacity. Hence it is reasonable to expect that the interaction with Arg330 will be far weaker and detrimental to substrate binding. In addition, the above mentioned possible dipolar interaction between $F_{3 \text { eq }}$ (in 5) and Gln206 is expected to be weaker due to its deshielding compared to $\mathrm{F}_{3 \text { eq }}$ in $\mathbf{4}$. $^{22}$

As a control experiment, we also examined whether the tetrafluorinated D-Gal analogue $\mathbf{5}$ could act as a competitive inhibitor by assaying D-Gal turnover in the presence of $\mathbf{5}$ (Supporting information). However the rate of oxidation of D-Gal $\mathbf{1}$ was not decreased in the presence of $\mathbf{5}$, confirming that 5 is a poor substrate for WT GOase compared to D-Gal.

In summary, a series of fluorinated galactose derivatives have been studied as substrates for WT GOase. 2-Deoxy-2,2difluoro $\mathbf{3}$ and 3-deoxy-3-fluoro galactose $\mathbf{4}$ were found to be good substrates for the enzyme. Remarkably, 4 has a lower $\mathrm{K}_{\mathrm{M}}$ value compared to D-galactose despite the replacement of an hydroxyl group that is thought to act as a hydrogen bond donor by a fluorine atom. However, comparison of the binding energies based on the specificity constants indicate a small loss for both 3 and 4. Significantly, it was found that 2,2,3,3tetrafluorinated galactose $\mathbf{5}$ was recognised by the enzyme, in contrast to the corresponding glucose analogue $\mathbf{6}$. This represents the first reported enzymatic transformation of a heavily fluorinated monosaccharide. However, compared to D-Gal, $\mathbf{5}$ is a relatively poor substrate, which was attributed to the strong electron withdrawing effect of the fluorine atoms on the 4-OH group. This results in a significant reduction in the hydrogen bond acceptor capacity of this alcohol group, thereby hampering an important interaction with Arg330.

We are grateful for funding from NovoNordisk, EPSRC and the Royal Society, as well as from the University of Southampton and ERASMUS/Siena University (EC). BL thanks Apollo Scientific for a generous gift of chemicals.

\section{Notes and references}

1 (a) C. P. J. Glaudemans, Chem. Rev., 1991, 91, 25; (b) R. U. Lemieux, Chem. Soc. Rev., 1989, 18, 347; (c) A. R Fersht, J.-P. Shi, J. Knill-Jones, D. M. Lowe, A. J. Wilkinson, D. M. Blow,
P. Brick, P. Carter, M. M. Y. Waye and G. Winter, Nature, 1985, 314, 235; (d) I. P. Street, C. R. Armstrong and S. G. Withers, Biochemistry, 1986, 25, 6021.

2 (a) K. Müller, C. Faeh and F. Diederich, Science, 2007, 317, 1881; (b) M. Zürcher and F. Diederich, J. Org. Chem., 2008, 73, 4345.

3 H. Dohi, R. Périon, M. Durka, M. Bosco, Y. Roué, F. Moreau, S. Grizot, A. Ducruix, S. Escaich and S. P. Vincent, Chem.-Eur. J., 2008, 14, 9530 .

4 (a) H. W. Kim, P. Rossi, R. K. Shoemaker and S. G. DiMagno, J. Am. Chem. Soc., 1998, 120, 9082; (b) J. C. Biffinger, H. W. Kim and S. G. DiMagno, ChemBioChem, 2004, 5, 622.

5 (a) S. Bresciani, T. Lebl, A. M. Z. Slawin and D. O'Hagan, Chem. Commun., 2010, 46, 5434; (b) B. Linclau, A. J. Boydell, R. S. Timofte, K. J. Brown, V. Vinader and A. C. WeymouthWilson, Org. Biomol. Chem., 2009, 7, 803; (c) L. Bonnac, S. E. Lee, G. T. Giuffredi, L. M. Elphick, A. A. Anderson, E. S. Child, D. J. Mann and V. Gouverneur, Org. Biomol. Chem., 2010, 8, 1445; (d) R. S. Timofte and B. Linclau, Org. Lett., 2008, 10, 3673; (e) A. J. Boydell, V. Vinader and B. Linclau, Angew. Chem., Int. Ed., 2004, 43, 5677.

6 By studying the transport of 2,3,4-trideoxy-2,3,4-trifluoroglucose across erythrocyte membranes (ref. 5a), ${ }^{19} \mathrm{~F}$ NMR indicated the presence of a metabolite; D. O'Hagan, personal communication.

7 (a) G. Avigad, D. Amaral, C. Asensio and B. L. Horecker, J. Biol. Chem., 1962, 237, 2736; (b) J. W. Whittaker, Chem. Rev., 2003, 103, 2347.

8 (a) J. B. Rannes, A. Ioannou, S. C. Willies, G. Grogan, C. Behrens, S. L. Flitsch and N. J. Turner, J. Am. Chem. Soc., 2011, 133, 8436; (b) M. D. Truppo, F. Escalettes and N. J. Turner, Angew. Chem., Int. Ed., 2008, 47, 2639; (c) N. J. Turner, Chem. Rev., 2011, 111, 4073.

9 F. Escalettes and N. J. Turner, ChemBioChem, 2008, 9, 857.

10 (a) N. Ito, S. E. V. Phillips, C. Stevens, Z. B. Ogel, M. J. McPherson, J. N. Keen, K. D. S. Yadav and P. F. Knowles, Nature, 1991, 350, 87; (b) R. M. Wachter and B. P. Branchaud, J. Am. Chem. Soc., 1996, 118, 2782.

11 S. E. Deacon, K. Mahmoud, R. K. Spooner, S. J. Firbank, P. F. Knowles, S. E. V. Phillips and M. J. McPherson, ChemBioChem, 2004, 5, 972.

12 (a) K. Aisaka, T. Uwajima and O. Terada, Agric. Biol. Chem., 1984, 48, 1425; (b) R. A. Schlegel, C. M. Gerbeck and R. Montgomery, Carbohydr. Res., 1968, 7, 193; (c) A. Maradufu and A. S. Perlin, Carbohydr. Res., 1974, 32, 93.

13 B. Linclau, S. Golten, M. Light, M. Sebban and H. Oulyadi, Carbohydr. Res., 2011, 346, 1129.

14 (a) J. D. McCarter, M. J. Adam, C. Braun, M. Namchuk, D. Tull and S. G. Withers, Carbohydr. Res., 1993, 249, 77; (b) C. G. Francisco, C. C. González, N. R. Paz and E. Suárez, Org. Lett., 2003, 5, 4171.

15 (a) J. S. Brimacombe, A. B. Foster, R. Hems and L. D. Hall, Carbohydr. Res., 1968, 8, 249; (b) J. N. Barlow and J. S. Blanchard, Carbohydr. Res., 2000, 328, 473.

16 (a) D. O'Hagan, Chem. Soc. Rev., 2008, 37, 308; (b) S. Purser, P. R. Moore, S. Swallow and V. Gouverneur, Chem. Soc. Rev., 2008, 37, 320; (c) C. M. Timperley and W. E. White, J. Fluorine Chem., 2003, 123, 65; (d) B. E. Smart, J. Fluorine Chem., 2001, 109,3 .

17 (a) M. H. Abraham, P. P. Duce, D. V. Prior, D. G. Barratt, J. J. Morris and P. J. Taylor, J. Chem. Soc., Perkin Trans. 2, 1989, 1355; (b) C. Laurence, K. A. Brameld, J. Graton, J.-Y. Le Questrel and E. Renault, J. Med. Chem., 2009, 52, 4073.

18 S. G. Withers, I. P. Street and S. J. Rettig, Can. J. Chem., 1986, 64, 232.

19 Recent review: M. Nishio, Phys. Chem. Chem. Phys., 2011, 13, 13873.

20 A. Fersht, in Structure and Mechanism in Protein Science, W. H. Freeman and Co, New York, 1998, pp. 341.

21 (a) N. Hayashi, T. Mori and K. Matsumoto, Chem. Commun., 1998, 1905; (b) W. B. Motherwell, J. Moïse, A. E. Aliev, M. Nic, S. J. Coles, P. N. Horton, M. B. Hursthouse, G. Chessari, C. A. Hunter and J. G. Vinter, Angew. Chem., Int. Ed., 2007, 46, 7823; (c) S.-i. Kawahara, S. Tzuzuki and T. Uchimaru, J. Phys. Chem. A, 2004, 108, 6744.

22 C. Dalvit and A. Vulpetti, ChemMedChem, 2011, 6, 104 